\title{
(1-10) Prediction of Combustion and In-Cylinder Emissions in a Direct Injection Diesel Engine Using Multi-Process Models
}

\author{
Pramod S Mehta* and Tamma Bhaskar \\ Internal Combustion Engines Laboratory \\ Department of Mechanical Engineering \\ Indian Institute of Technology Madras \\ Chennai-600036, INDIA
}

Key words: Direct Injection Diesel Engines, Combustion, Emissions, Soot Modeling

\begin{abstract}
Though experimental work helps in resolving many of the issues related to soot emissions, an analytical approach enables in-depth understanding of the mechanisms and principles of soot formation. In this work, an attempt is made to predict in-cylinder nitric oxide (NO) and soot concentrations using a multi-zone diesel combustion model. For estimating soot formation, the conservation equations for precursor specie, growth specie, soot volume fraction and particle number density are solved in each spray zone. The total in-cylinder NO and soot concentrations are obtained by summing up their values in each zone of the spray. The model predictions are compared with the experimental data available in literature [15]. Typical results of a comparison of energy release, cylinder pressure and in-cylinder NO and soot concentrations at a reference test condition of $-8^{\circ}$ atdc injection timing and $29.6 \mathrm{mg} /$ cycle fuelling rate are shown in figures below. The predicted and experimental values of these quantities are in reasonable agreement with each other and thus confirm the ability of the proposed model to predict engine combustion and emission characteristics.
\end{abstract}

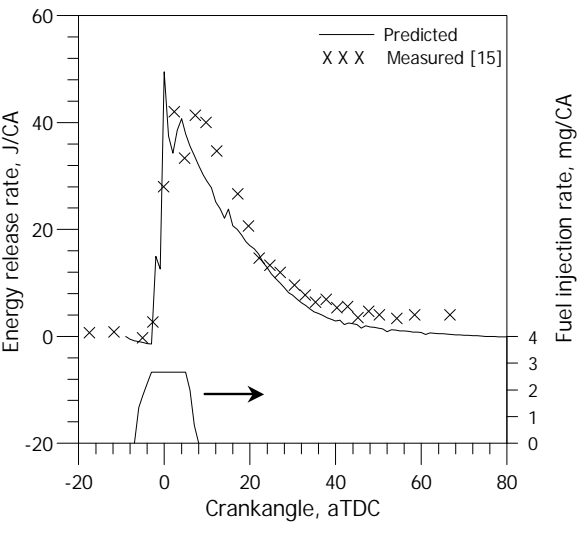

Comparison of predicted and measured energy release rate

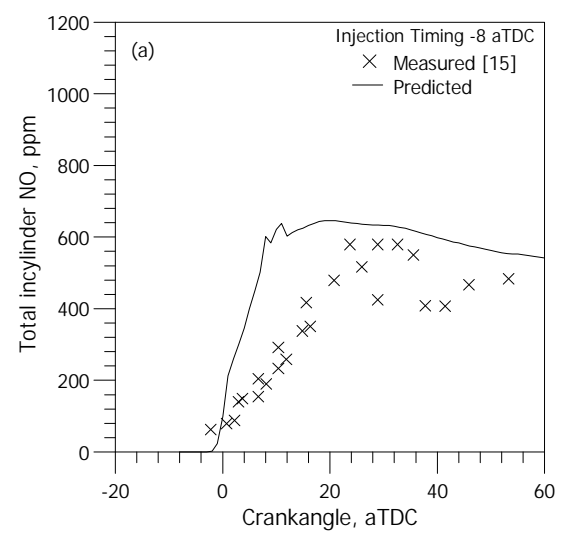

Comparison of predicted and measured NO emission

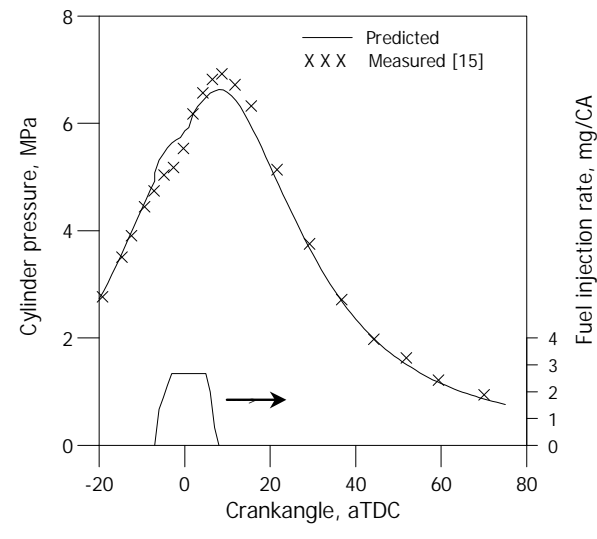

Comparison of predicted and measured cylinder pressures

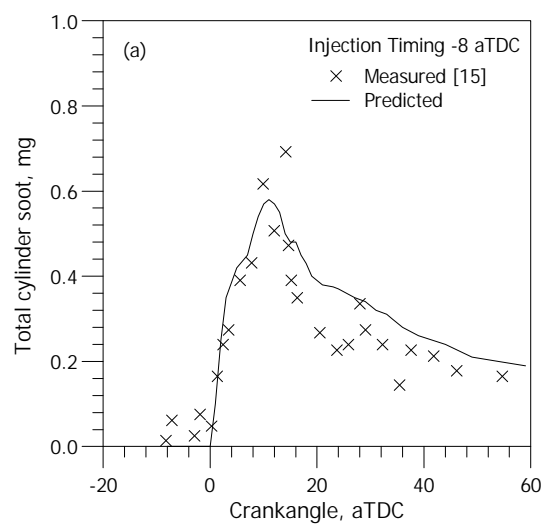

Comparison of predicted and measured total in-cylinder soot 


\section{INTRODUCTION}

Due to fuel economy advantages of Direct Injection (DI) diesel engines, there are intense research efforts ongoing in the combustion and emission aspects of this variety of engine. Nitric oxide (NO) and soot are the two major pollutants in the diesel engine exhaust. It is known that the simultaneous reduction of $\mathrm{NO}$ and soot is rather difficult due to the opposite influences of several engine design and operating conditions on their formation. While conditions and mechanisms of nitric oxide formation are fairly established, the details of soot formation mechanism are not yet understood. There is no general agreement on a single model for soot formation and oxidation processes as yet. Among the variety of soot prediction approaches [1], it is found that global kinetic rate equation based soot correlations are engine specific and lack generality while the two-step rate equation model [2] is solely particle based and does not incorporate the mass production. In these respect, the multi-process soot models appear promising as they consider several physio-chemical processes concerning soot formation and are being currently validated with multi-dimensional combustion models. However, there is no available study concerning the use of multiprocess soot models with multi-zone fuel-air spray mixing and combustion models. Hence in this work, an attempt is made to predict soot emissions using a multiprocess single step scheme in conjunction with a multizone combustion model.

\section{MODEL FORMULATION}

The present formulation has been developed based on a phenomenological approach involving fuel-air mixing, combustion and emission processes.

\section{Fuel-Air Mixing Model}

In the model configuration, the combustion chamber space is divided into two distinct regions spray and surrounding. The spray growth is a result of an interaction of injected fuel with the incylinder air. In case of swirling air, the spray will be deflected due to the effect of air momentum. Also, the momentum exchange between the fuel spray and air results in air entrainment causing the fuel-air mixing. In the present work, a transient, multi-zone, quasi-steady, axisymmetric spray model is used for the fuel-air mixing in the spray [3]. A schematic of the spray-air interaction in the engine cylinder is shown in figure 1 . The model uses integro-differential forms of, conservation equations for fuel mass, total spray mass, and tangential and normal components of spray momentum as given in Appendix A. These equations are solved simultaneously for jet radius, mass concentration and velocity along the spray centreline using modified Euler's method. The fuel air mixing model provides spatial fuel concentration in the spray. The model also includes evaporation calculations with drop size distributions based on references [4-5].

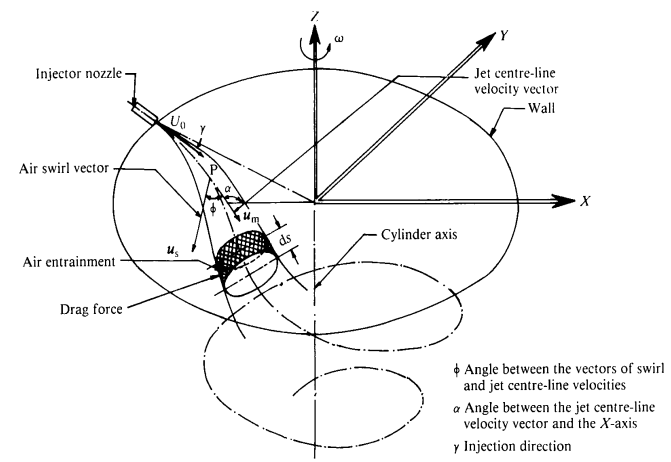

Figure 1 Schematic of spray and swirl interaction [3]

\section{Combustion Model}

In an earlier attempt [6], the eddy dissipation mode [EDM] of Magnussen et al [7] was used to predict fuel burning rate during both premixed and diffusion phases of diesel combustion. However, the approach was found inadequate in predicting the occurrence of first peak in premixed combustion phase. To overcome this difficulty, separate burning rate equations are written for premixed and diffusion phases of diesel engine combustion. Since the amount of fuel burned in the premixed phase is the amount of fuel that has evaporated, mixed and formed ignitable mixture at the end of ignition delay and the combustion in this phase is mainly kinetically controlled, a bimolecular reaction rate equation [8] has been used to evaluate the fuel mass burning rate during this phase as:

$$
\frac{d m_{f, b}}{d t}=A_{p} m_{f}^{0.25} m_{o 2}^{1.5} \exp \left(-\frac{E_{A}}{R_{u} T}\right) V_{z}^{-0.75}
$$

where $A_{p}$ is the pre-exponential constant $\left(6.83 \times 10^{6}\right.$ $\left.\mathrm{kg}^{-0.75} \mathrm{~m}^{-2.25} \mathrm{~s}^{-1}\right), E_{A}$ is the activation energy (=132 $\mathrm{MJ} / \mathrm{kmol}$ ), $T$ is the temperature, $R_{u}$ is the universal gas constant, $V_{z}$ is the volume of the zone, and $m_{f}$ and $m_{O 2}$ are the total mass of fuel and oxygen.

The estimation of fuel mass burning rate during diffusion phase followed the eddy dissipation model [7], expressing the rate of fuel burning in lean or rich mixture conditions, as

$\frac{d m_{f, b}}{d t}=\frac{A_{c}}{\tau_{b}} \min \left[m_{f}, \frac{m_{O_{2}}}{\left(O_{2} / f\right)_{s t}}\right]$

where $A_{c}(=0.15)$ is an empirical constant, $m f$ and $m_{O 2}$ are mass of fuel and oxygen respectively and $\tau_{b}$ is the burn time and is evaluated as geometric mean of mixing $\left(\tau_{m}\right)$ and Kolmogorov $\left(\tau_{k}\right)$ time scales [9] as

$$
\tau_{b}=\sqrt{\tau_{m} \cdot \tau_{k}}
$$

Both the mixing time scales are obtained in terms of turbulent kinetic energy $(\mathrm{k})$, its dissipation $\operatorname{rate}(\varepsilon)$ and charge viscosity (v) as:

$$
\begin{aligned}
& \tau_{m}=\frac{k}{\varepsilon} \\
& \tau_{k}=\left(\frac{v}{\varepsilon}\right)^{0.5}
\end{aligned}
$$


A quasi- steady $\mathrm{k}-\varepsilon$ turbulence model [10] is used for evaluating the turbulence quantities. The sources of turbulence considered in $\mathrm{k}-\varepsilon$ turbulence model include intake, swirl, squish, fuel injection and combustion. Their characterization details are given elsewhere[6]

\section{Emissions Model}

While calculation of NO concentration is based on modified Zeldovich mechanism, the prediction of soot formation is carried out through a multi-process model [11] in conjunction with an existing soot oxidation model. Among oxidation models, the NSC scheme [12] supported by a model for oxidation with $\mathrm{OH}$ radical $[13,14]$ is used. For estimating soot formation, the conservation equations for precursor specie (R), growth specie $\left(\mathrm{C}_{2} \mathrm{H}_{2}\right)$, soot particle number density (PND) and soot volume fraction (SVF) are respectively expressed as:

$$
\begin{aligned}
& \frac{d[R]}{d t}=R_{1}-R_{2}-R_{6} \\
& \frac{d\left[C_{2} H_{2}\right]}{d t}=-R_{3}+R_{4}-R_{7} \\
& \frac{d(P N D)}{d t}=N_{A} R_{2}-R_{5} \\
& \frac{d(S V F)}{d t}=\frac{1}{\rho_{s}}\left[R_{2} M_{R}+R_{3} M_{C}-\left(R_{8}+R_{9}\right) M_{C}\right]
\end{aligned}
$$

where $R_{1}$ to $R_{9}$ are the reaction rates of various soot processes specified in Appendix B, $\rho_{s}$ is the soot density, $N_{A}$ is the Avogadro number, $M_{C}$ is the molecular mass of the carbon, $M_{R}$ is the molecular mass of radical precursor.

The values for pre-exponential constants, activation energies and other coefficients used for various soot formation rate equations are also provided in Appendix B. These equations are solved for each zone in the spray.

The solution of these first order differential equations 6 through 9, in terms of various rate equations, based on soot processes provides the spatial and temporal distribution of soot concentration in the combustion chamber. The proposed model predicts both particles and mass concentrations simultaneously.

\section{RESULTS AND DISCUSSION}

The results concerning the model validation on a direct injection diesel engine are discussed here. The fuel-air mixing characteristics have not been included in this paper as that aspect has been extensively discussed in reference [3]. The experimental data of Pipho et al [15] on a direct injection diesel engine, specified in Table 1, have been used to validate results concerning energy release, cylinder pressure and in-cylinder NO and soot concentrations.

Figures 2 and 3 show a comparison of the predicted energy release rate and the cylinder pressure histories for the engine and its operating conditions specified in Table 1. The injection schedule for the reference data has been taken from Hou and Abraham [16] and shown with both energy release and cylinder pressure diagrams on figures 2 and 3. The predictions with the present combustion model are in fairly good agreement with the experimental results. The trends of predicted energy release during various phases in diesel combustion are found to be consistent and the predicted cylinder pressures are in good agreement with the experimental data.

Table 1: Engine specifications and test conditions [15]

\begin{tabular}{|l|lc|}
\hline Engine & \multicolumn{3}{|l|}{ 4-stroke, DI, 4 cylinder } \\
Bore & 0.093 & $\mathrm{~m}$ \\
Stroke & 0.102 & $\mathrm{~m}$ \\
Speed & 1500 & $\mathrm{rpm}$ \\
Compression ratio & 18.6 & \\
Displacement & $692.9 \times 10^{-12}$ & $\mathrm{~m}^{3} / \mathrm{cyl}$ \\
Injection timing & -8 & $\mathrm{aTDC}$ \\
Fuel injection rate & 29.6 & $\mathrm{mg} / \mathrm{cycle}$ \\
Injector details & & \\
Number of nozzle & 4 & $\mathrm{~m}$ \\
Nozzle diameter, m & 0.00028 & $\mathrm{MPa}$ \\
Nozzle opening pressure & 18.1 & \\
Piston bowl & Squared with reentrant lip \\
Intake swirl ratio & 1.5 & \\
Fuel & Diesel Fuel No.2 \\
Density & 840 & $\mathrm{~kg} / \mathrm{m}^{3}$ \\
Net calorific value & $43 \times 10^{6}$ & $\mathrm{~J} / \mathrm{kg}$ \\
Cetane number & 40 & \\
\hline
\end{tabular}

Figures 4(a) and 5(a) show the comparison of NO and soot predictions with the experimental results at the same operating conditions. Pipho et al [15] have used total cylinder sampling method to study the formation of soot and NO emissions. This sampling methodology provides measurable sample of soot and spatially averaged concentration of combustion products.

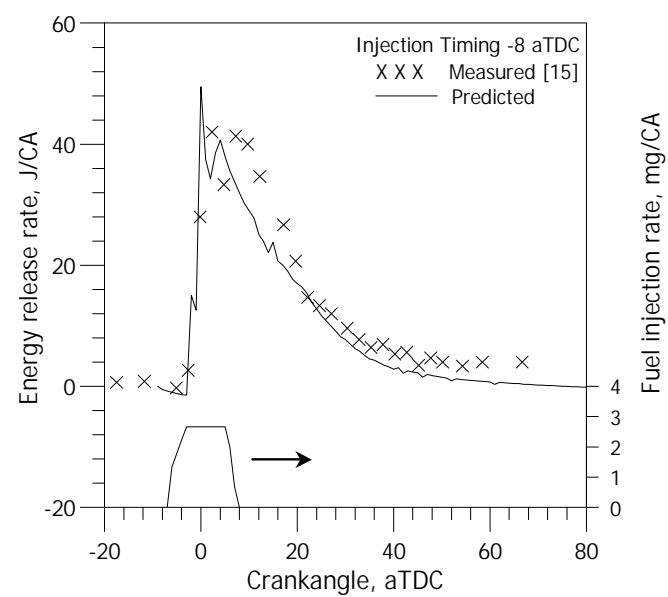

Figure 2: Comparison of predicted and measured energy release rate at standard test conditions

Due to high temperatures resulting from premixed phase combustion, the NO formation rates are found to be very high in the initial stages of combustion (Figure 4(a)). The higher values of predicted NO concentration in the initial stage of combustion at reference and other injection conditions are primarily due to the higher 
predicted values of cylinder pressure and temperature histories during premixed combustion period. After reaching a peak, the NO concentration flattens due to continuous air entrainment into the spray leading to the lowering of temperature.

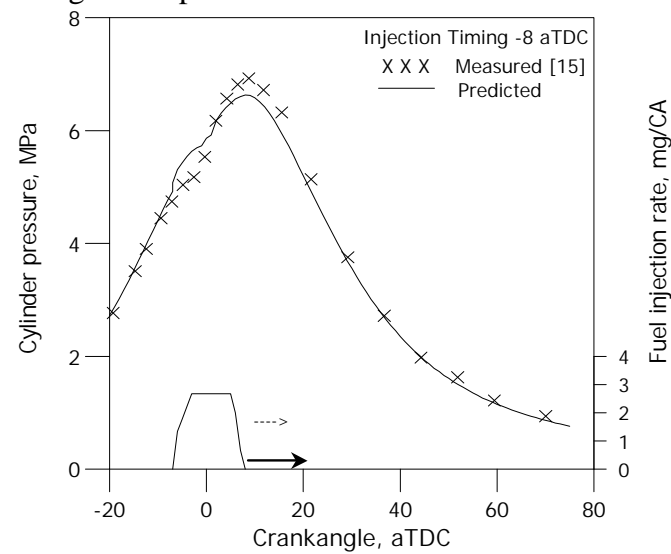

Figure 3: Comparison of predicted and measured cylinder pressure at standard test condition

At standard injection timing of $-8 \mathrm{deg}$ aTDC, the soot formation occurs at 3 degrees $\mathrm{CA}$ after ignition (ignition delay is $-6^{\circ} \mathrm{CA}$ ) (see Figure 5(a)). Since the model assumes that soot formation does not occur during this premixed phase, hence the predicted incylinder soot concentration lags the experimental soot values consistently in all cases. The duration of $3^{\circ} \mathrm{CA}$ after ignition is mainly the period of premixed combustion. As fuel burning progresses in diffusion phase, the soot concentration increases rapidly and reaches a maximum at about 12 degrees aTDC. During this phase first soot nucleation and surface growth processes are controlling and beyond the peak soot value, the soot oxidation process dominates. The soot oxidation continues throughout the expansion process eventually a very small fraction of soot remains in the exhaust process. This means a significant amount of soot formed, as can be seen from its peak value, combusts during the expansion process.

Beside, these emission results, the remaining two curves in Figures 4(b-c) and 5(b-c) show the comparison of predicted and measured results concerning NO and soot at advanced (-11 aTDC) and retarded ( -5 aTDC) injection timings.

The higher premixed burning and the resultant higher temperatures with advanced injection timing lead to a high NO concentration as shown in Figure 4(b). Also the soot formation rates are higher during initial period of diffusion combustion (refer Figure 5(b)). This is attributed to the higher temperatures as a result of longer ignition delay at advanced injection timing. It may be observed that with advanced injection timing, the peak of soot mass occurs earlier compared to the standard injection condition. The longer oxidation time and the higher temperature for soot lowers the net soot mass towards the end of expansion.

It can be observed that at retarded injection timing, the NO emission levels are lower (Figure 4(c)) compared to the standard or advanced injection timings. Figure 5(c) shows total cylinder soot mass at retarded timing of -5 aTDC. The ignition starts around TDC and the amount of premixed burning is also low due to lower ignition delay. These conditions lead to low temperatures and hence the lower soot mass (Figure $5(\mathrm{c}))$. Soot emission is a result of two competitive process viz. formation and oxidation. It can be said that a longer combustion period at retarded injection timing, extends the soot formation period for a significant part in the expansion stroke and results in slower drop in soot mass. At retarded injection timing, the soot mass towards the end of expansion is observed to be higher compared to standard or advanced injection timings. A comparison of predicted and exhaust soot emission for these three injection timings is given in Table 2. These confirm the expected variations.

Table 2 Comparison of measured [15] and predicted exhaust soot mass (in $\mathrm{mg}$ )

\begin{tabular}{|c|c|c|}
\hline Inj. Timing, aTDC & Measured [15] & Predicted \\
\hline-5 & 0.136 & 0.144 \\
\hline-8 & 0.126 & 0.135 \\
\hline-11 & 0.116 & 0.101 \\
\hline
\end{tabular}

It can be seen from the above discussion, that the influence of injection timing on in-cylinder and exhaust emissions is very significant. While retarded timing leads to lower NO emission, soot emission is higher in the exhaust and vice versa at advanced injection timings.

These limited comparison provide confidence in model capability of predicting in-cylinder emission. The overall comparison of measured and predicted exhaust soot results show a good agreement qualitatively and quantitatively. The NO emission predictions are also found to be in reasonable agreement with the measured data.

\section{CONCLUSIONS}

A multizone phenomenological model for direct injection diesel engine combustion has been developed incorporating i) spray mixing model during injection, involving droplet evaporation and fuel spray- air swirl interactions, ii) two-equation $\mathrm{k}-\varepsilon$ turbulence model, iii)heterogeneous combustion rate model based on kinetics and eddy dissipation concept, and iv) singlestep kinetic rate model for soot processes.

Subsequent to the model development, the predictions from these models are compared with the available experimental data. The following conclusions are drawn:

- The cylinder pressure predictions are within \pm 5 percent of the experimental pressures at all the test conditions. The energy release rate diagrams follow the expected trends.

- The predicted incylinder and exhaust soot and NO emissions are generally in good agreement with the experimental data. 
- The model predictions for the injection timing effects on soot and NO emissions have compared well with experimental results.
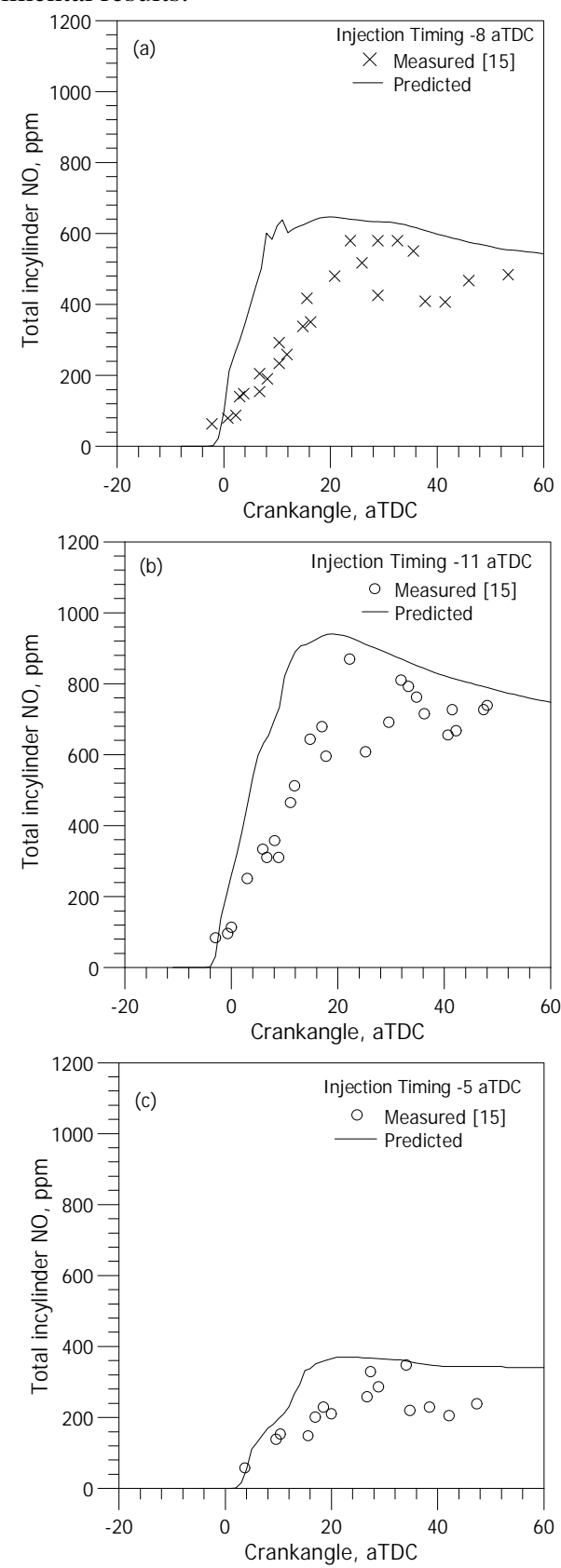

Figure 4: Comparison of predicted and measured total incylinder $\mathrm{NO}$ at different injection timings

\section{NOMENCLATURE}

A Spray cross sectional area, $\mathrm{m}^{2}$

$\mathrm{A}_{\mathrm{c}} \quad$ Empirical constant

$\mathrm{A}_{\mathrm{p}} \quad$ Pre-exponential constant, $\mathrm{kg}^{-075} \mathrm{~m}^{-2.25} \mathrm{~s}^{-1}$

$\mathrm{C}$ fuel concentration

$\mathrm{E}_{\mathrm{A}} \quad$ Activation energy, $\mathrm{J} \mathrm{kmol}^{-1}$

$\mathrm{k} \quad$ Turbulent kinetic energy, $\mathrm{m}^{2} \mathrm{~s}^{-2}$

$\mathrm{M}_{\mathrm{C}} \quad$ Molecular weight of the carbon, $\mathrm{kg} \mathrm{kmol}^{-1}$

m Mass, $\mathrm{kg}$

$\mathrm{M}_{\mathrm{R}} \quad$ Molecular mass of radical precursor, $\mathrm{kg} \mathrm{kmol}^{-1}$

$\mathrm{N}_{\mathrm{A}} \quad$ Avogadro number $\left(=6.02 \times 10^{26} \mathrm{~mol} . \mathrm{kmol}^{-1}\right)$
- The exhaust soot emissions have been predicted for different injection timing. Their comparison with experimental data is found in good agreement.
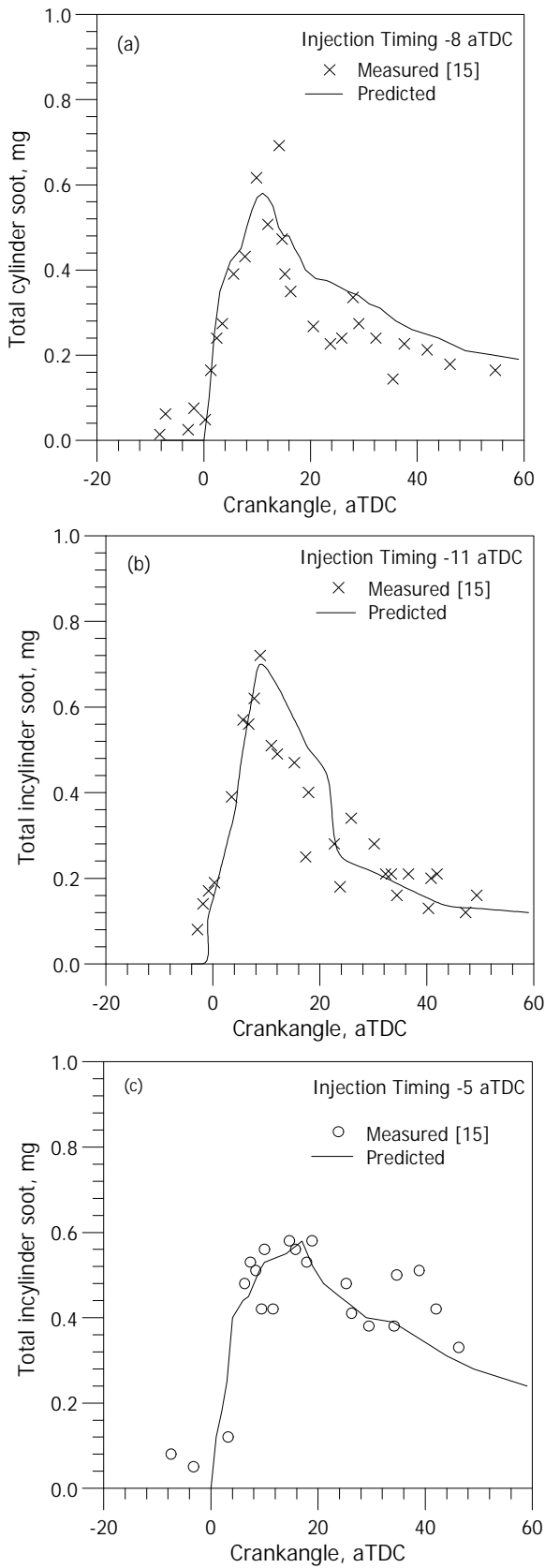

Figure 5: Comparison of predicted and measured total incylinder soot at different injection timings

$\mathrm{p} \quad$ Pressure, $\mathrm{Pa}$

PND Particle number density, $\mathrm{m}^{-3}$

$\mathrm{R} \quad$ Precursor specie

$\mathrm{R}_{1}-\mathrm{R}_{9} \quad$ Rate constants, $\mathrm{kmol} \mathrm{m} \mathrm{s}^{-3}$

$\mathrm{R}_{\mathrm{u}} \quad$ Universal gas constant $\left(=8314.3 \mathrm{~J} \mathrm{kmol}^{-1} \mathrm{~K}^{-1}\right)$

SVF Soot volume fraction

$\mathrm{T}$ Temperature, $\mathrm{K}$

$\mathrm{t}$ Time, $\mathrm{s}$

V Volum, $\mathrm{m}^{3}$

y Normalised radial distance

$\varepsilon \quad$ Dissipation rate, $\mathrm{m}^{2} \mathrm{~s}^{-3}$ 


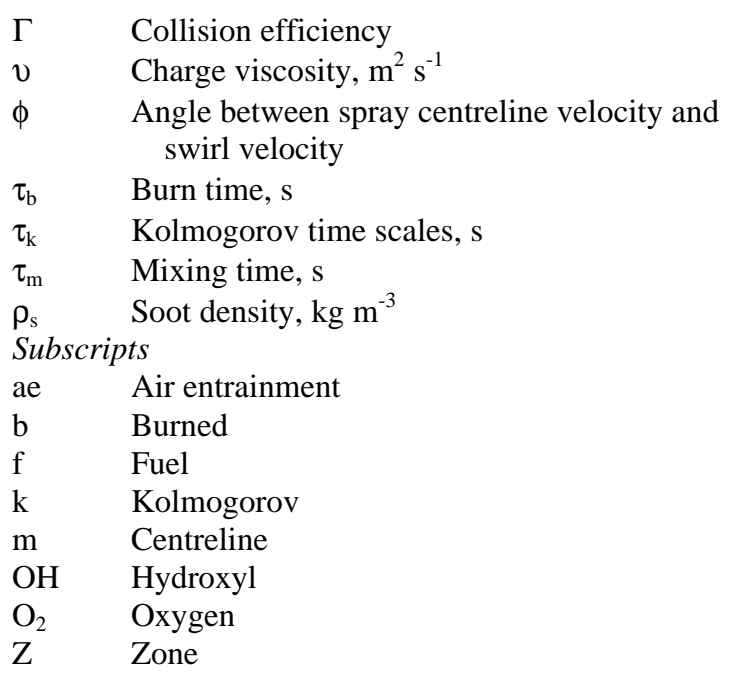

\section{REFERENCES}

1 Bhaskar T. and Mehta P.S.,"A Critical Appraisal of Soot Modelling Approached for Diesel Engines", Proceedings of the XIV National Conference on I.C. Engines and Combustion, IAT Pune,1995,pp137-143.

2 Tesner P.A., Snegiriova T.D., and Knorre V.G., "Kinetics of dispersed carbon formation", Combustion and Flame, 17, (1971), 253-260.

3 Mehta P.S. and Gupta A.K., "Modeling of SpraySwirl Interaction in Direct Injection Diesel Engine Combustion Chambers", Proc. I. Mech E, 199, D3, (1985), 187-197.

4 Chin J. S. and Lefebvre A. H., "Steady-State Evaporation Characteristics of Hydrocarbon Fuel Drops", AIAA Jl., 21, , (1983)1437- 1443.

5 Simmons H.C., "The Correlation of Drop-Size Distribution in Fuel Nozzle Sprays - Part II: The Dropsize / Number Distribution", ASME Jl of Engineering for Power, 199, (1977), 315-319.

6 Bhaskar T. and Mehta P. S., "A Multi-Zone Diesel Combustion Model Using Eddy Dissipation Concept" Proceedings Fourth International Symposium on Diagnostics and Modeling of Combustion in Internal Combustion Engines (COMODIA), Kyoto, (1998), pp 135-140.

7 Magnussen B.F. and Hjertager B.H., "On Mathematical Modeling of Turbulent Combustion with Special Emphasis on Soot Formation and Combustion", Sixteenth Symposium (International) on Combustion, The Combustion Institute, Pittsburg, PA, (1977), pp 719- 729.

8 Xin J., Montgomery D., Han Z and Reitz R.D., "Multidimensional Modeling of Combustion for a Six-Mode Emissions Text Cycle on a DI Diesel Engine", Trans ASME Jl of Engineering for Gas Turbines and Power, 119, (1997), 683-691.

9 Chomiak, J. and Karlsson J.A.J., "Flame Lift-off in Diesel Sprays", Twenty sixth Symposium (International) on Combustion, The Combustion Institute, Pittsburg, PA, (1996), pp 2557-2564
10 Bhaskar $\mathrm{T}$ and Mehta P. S., "Prediction of Turbulence in a Motored DI Diesel Engine Using a Quasi-Dimensional k- $\varepsilon$ Model",Proceedings ASME 1997 Spring Engine Technology Conference, Fort Collins, CO, USA, (1997), pp45-50

11 Fusco A., Knox-Kelecy A. L. and Foster D. E., "Application of a Phenomenological Soot Model to Diesel engine Combustion", Proceedings of the Fourth International Symposium on Diagnostics and Modeling of Combustion in Internal Combustion Engines(COMODIA), Yokohoma(1994),pp 571-576.

12 Nagle J. and Strickland-Constable R. F., "Oxidation of Carbon Between 1000- 2000 C", Proceedings of Fifth Carbon Conference, Vol 1, (1962), pp 154-164.

13 Haudiquert M., Cessou A., Stepowski D. and Coppalle A., "OH and Soot Concentration Measurements in a High-Temperature Laminar Diffusion Flame" Combustion and Flame, 111, (1997), 338-349.

14 Yoshihara Y., Kazakov A., Wang H,. and Frenklach M., "Reduced mechanism of soot formation- Application to natural gas fueled diesel combustion", Twenty Fifth Symposium (International) on Combustion, The Combustion Institute, Pittsburg, PA, (1994), pp 941- 948.

15 Pipho M. J., Kittelson D. B., Luo L. and Zarling D. D., "Injection Timing and Bowl Configuration Effects on Incylinder Particle Mass" SAE Trans. Paper No. 921646, (1992), 1703-1718

16 Hou Z. X. and Abraham J., "Three Dimensional Modelling of Soot and NOx in a Direct Injection Diesel Engine”, SAE Trans. Paper No.950608(1995)

17 Hiroyasu H.,Kadota T. and Arai M., "Supplementary Comments- Fuel Spray Characterisation in Diesel Engines" Combustion Modeling in Reciprocating Engines, Mattavi J.N. and Amman C.A.(eds), Plenum Press,(1980), pp 369-408.

18 Ricou F.P. and Spalding D.B. "Measurements of Entrainment by Axisymmetric Turbulent Jets", Jl of Fluid Mechanics, 9, 21-32 (1961)

\section{ACKNOWLEDGEMENT}

The authors wish to acknowledge the financial support received from the Department of Science and Technology, Government of India for this work.

\section{APPENDIX A: Fuel-Air Mixing Model}

Mass Conservation

The mass conservation of fuel and total spray mass (fuel+air)at any cross section of the spray are written as: $\frac{d}{d S}\left[\int c \rho u d A\right]=0$

$\frac{d}{d S}\left[\int \rho u d A\right]=\frac{d \dot{m}_{a e}}{d S}$

Momentum Conservation

The tangential and normal components of spray momentum are respectively written as : 
$\frac{d}{d S}\left[\cos (\alpha) \int \rho u^{2} d A\right]=\omega r \cos (\phi) \frac{d \dot{m}_{a e}}{d S}$

$\frac{d}{d S}\left[\sin (\alpha) \int \rho u^{2} d A\right] \omega \omega r \sin (\phi) \frac{d \dot{m}_{a e}}{d S}$

where A is spray cross sectional area, c is local fuel concentration in spray $\left(=c_{m}\left(1-y^{1.5}\right)\right)$, $r$ is chord distance of cross section from the nozzle tip, $S$ is spray penetration, $u$ is local spray velocity $\left(=\mathrm{u}_{\mathrm{m}}\left(1-\mathrm{y}^{1.5}\right)^{2}\right)$, $\mathrm{y}$ is the non-dimensional radial distance from the spray centreline, $\rho$ is local spray density, $\omega$ is swirl speed in $\mathrm{rad} / \mathrm{s}, \phi$ is angle between spray centreline velocity and swirl velocity, and $\alpha$ is angle between spray centreline and $\mathrm{x}$-axis and the suffix $\mathrm{m}$ refers to values at spray centreline. The spray penetration (S) is calculated from correlation of Hiroyasu et al [17] and the air entrainment $\operatorname{rate}\left(\dot{\boldsymbol{m}}_{\mathrm{ae}}\right)$ following Ricou and Spalding[18]

\section{APPENDIX B: Soot Processes and their Rate Equations}

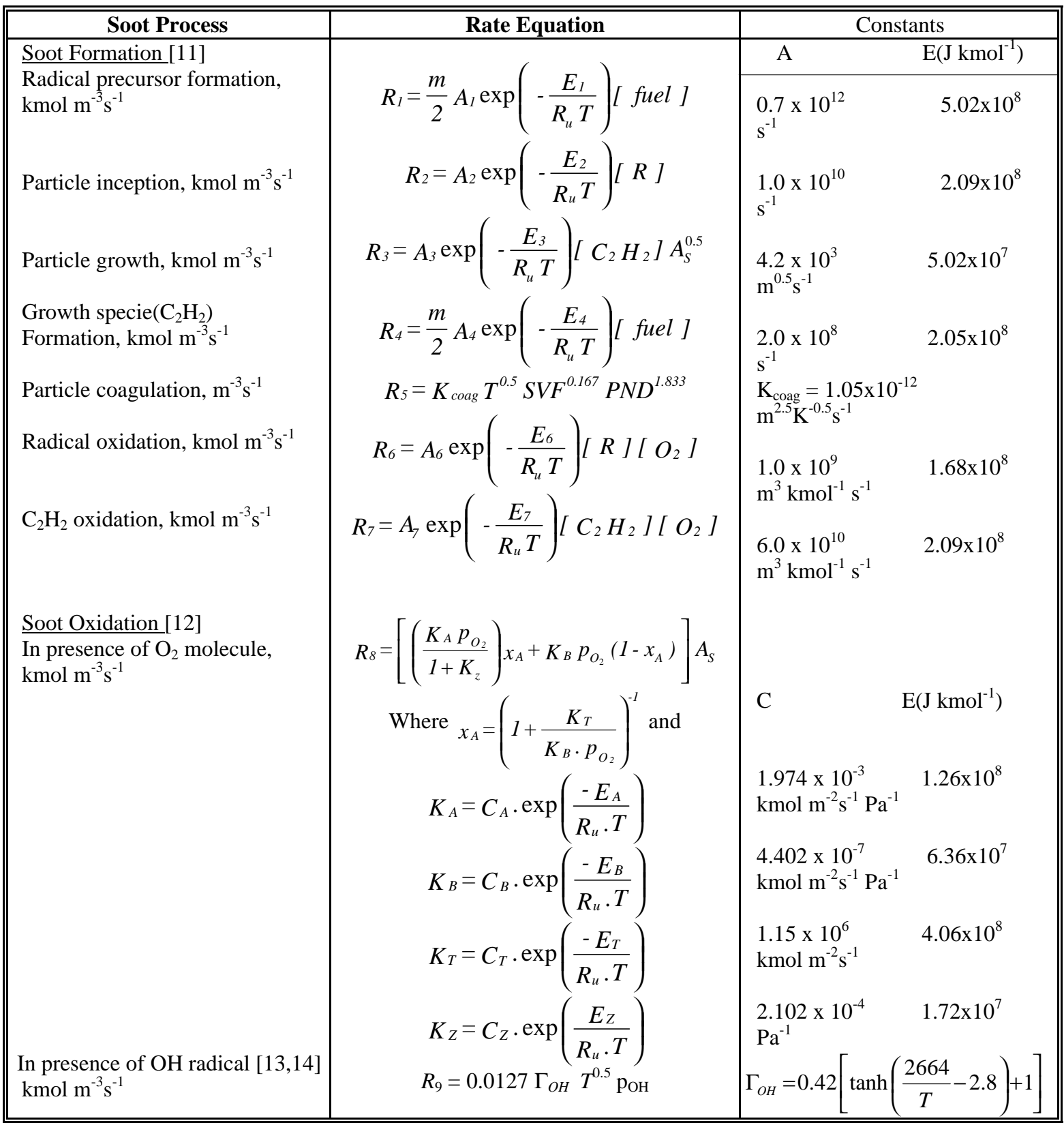

where $T$ is local temperature, $[R]$ is radical precursor, $S V F$ is soot volume fraction, [fuel] and $\left[O_{2}\right]$ are the fuel and oxygen concentrations respectively, $m$ is fuel carbon number, $p_{\mathrm{O}_{2}}$ and $p_{\mathrm{OH}}$ is partial pressure of $\mathrm{O}_{2}$ and $\mathrm{OH}, \mathrm{R}_{u}$ is universal gas constant $A_{S}$ is total soot surface area and $P N D$ is the soot particle number density. 